\section{EBM}

ONLINE

\title{
Review: clinical examination is often as accurate as magnetic resonance imaging for diagnosing meniscus tears
}

Michael Yelland

Evid. Based Med. 2007;12;151-

doi:10.1136/ebm.12.5.151

Updated information and services can be found at:

http://ebm.bmj.com/cgi/content/full/12/5/151

These include:

References This article cites 3 articles, 1 of which can be accessed free at:

http://ebm.bmj.com/cgi/content/full/12/5/151\#BIBL

Rapid responses You can respond to this article at:

http://ebm.bmj.com/cgi/eletter-submit/12/5/151

Email alerting Receive free email alerts when new articles cite this article - sign up in the box at service the top right corner of the article

Notes

To order reprints of this article go to:

http://journals.bmj.com/cgi/reprintform

To subscribe to Evidence-Based Medicine go to:

http:/journals.bmj.com/subscriptions/ 


\section{Review: clinical examination is often as accurate as magnetic resonance imaging for diagnosing meniscus tears}

Ryzewicz M, Peterson B, Siparsky PN, et al. The diagnosis of meniscus tears: the role of MRI and clinical examination. Clin Orthop Relat Res 2007;455:123-33.

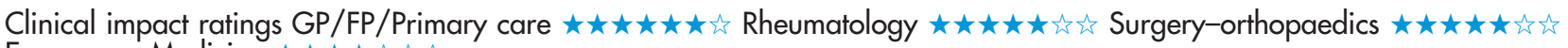

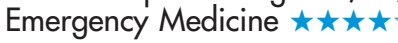

In patients with knee injury, how accurate are clinical examination and magnetic resonance imaging (MRI) for diagnosing meniscus tears compared with arthroscopy? Can MRI be used to reduce the number of patients with negative arthroscopy?

\section{METHODS}

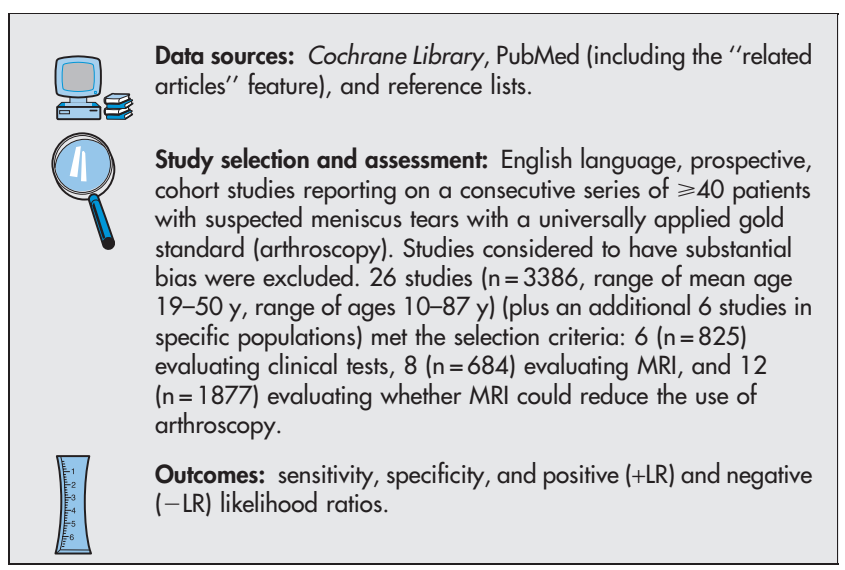

\section{MAIN RESULTS}

The table shows the diagnostic test characteristics of several clinical tests and MRI. Of the 12 studies that compared the accuracy of clinical examination and MRI for diagnosing meniscus tears, 5 studies $(n=1100)$ concluded that MRI was more accurate than clinical examination; thus, its routine use could substantially reduce the number of unnecessary arthroscopic procedures performed. The other 7 studies $(n=777)$ concluded that, in the hands of a skilled practitioner, clinical examination was at least as accurate as MRI, and that use of MRI should be reserved for patients in whom the clinical diagnosis is uncertain.

\section{CONCLUSIONS}

In the hands of an experienced clinician, clinical examination is often as accurate for diagnosing meniscus tears as magnetic resonance imaging. Based on available evidence, it is unclear whether routine use of MRI in patients with knee injuries can reduce the number of arthroscopies with negative findings. For correspondence: Dr R L Bartz, Nebraska Orthopaedic and Sports Medicine, Lincoln, NE, USA. rbartz@nebraskaortho.com

Source of funding: not stated

\section{Commentary}

T he review by Ryzewicz et al offers important information for clinicians faced with the difficulties of diagnosing and treating meniscal tears. It was based on a very extensive search for good quality literature assessing the diagnostic accuracy of clinical examination or MRI compared with arthroscopy, with limits set on the search to exclude studies with obvious bias.

Translation of the results of the review into clinical practice is limited by the reductionist nature of the research described. All but 1 of the studies analysed the accuracy of individual tests, whereas in clinical practice, decisions are based on a synthesis of history and examination findings. However, if the clinician is to rely on only 1 test, the best 2 to choose from are the Thessaly test, ${ }^{1}$ twisting on the knee flexed to 20 degrees, and the Ege test, ${ }^{2}$ squatting and rising with the knees externally rotated and then internally rotated. The accuracy of these tests is similar to that of MRI.

It is notable that the clinical examiners who achieved similar results to MRI in predicting the findings at arthroscopy were all highly experienced. This same level of accuracy may not be achieved by less experienced clinicians. Similarly, for MRI, the expertise of the radiologist should be considered. Nearly all the MRI studies used specialist musculoskeletal radiologists, who may diagnose tears more accurately than general radiologists. Both clinical examination and MRI are less accurate in paediatric, adolescent, and ageing knees and in the presence of acute knee injury, ligament injury, and osteoarthritis.

Ryzewicz et al concluded that careful examination by an experienced clinician is as good as, or better than, MRI in the detection of meniscal tears. This implies that patients may safely proceed to arthroscopy without an MRI, thereby keeping the MRI as backup in cases where further information is needed to make a diagnostic decision. Conversely, the clinical examination or MRI may obviate the need for a purely diagnostic arthroscopy. Arthroscopy can then be reserved for cases requiring treatment.

This review should motivate clinicians to raise their examination skills for diagnosing meniscal tears to a level where they can trust their own findings and, thereby, spare some of their patients the expense and inconvenience of MRI or arthroscopy without adversely affecting their outcome.

Michael Yelland, MB BS, PhD Griffith University Logan, Australia

1 Karachalios T, Hantes M, Zibis AH, et al. J Bone Joint Surg Am 2005;87:955-62

2 Akseki D, Ozcan O, Boya H, et al. Arthroscopy 2004;20:951-8.

Diagnostic test characteristics of clinical tests and magnetic resonance imaging (MRI) for meniscus tears of the knee*

\begin{tabular}{llllll}
\hline Tests & Number of studies $(\mathbf{n})$ & Sensitivity (range) & Specificity(range) & +LR (range) & - LR (range) \\
\hline McMurray test & $5(721)$ & $16 \%$ to $67 \%$ & $69 \%$ to $98 \%$ & 2.2 to 9.3 & 0.4 to 0.9 \\
Apley's test & $2(374)$ & $16 \%$ to $41 \%$ & $80 \%$ to $93 \%$ & 0.8 to 5.9 & 0.6 to 1.1 \\
Joint line tenderness & $4(628)$ & $67 \%$ to $92 \%$ & $29 \%$ to $97 \%$ & 1.2 to 31 & 0.1 to 0.5 \\
Thessaly's test & $1(213)$ & $66 \%$ to $92 \%$ & $91 \%$ to $97 \%$ & 9 to 30 & 0.1 to 0.4 \\
Ege's test & $1(150)$ & $64 \%$ to $67 \%$ & $81 \%$ to $90 \%$ & 3.5 to 6.4 & 0.4 \\
MRI & $8(684)$ & $40 \%$ to $100 \%$ & $66 \%$ to $100 \%$ & 2.2 to $\infty$ & 0 to 0.6 \\
\hline
\end{tabular}

*Diagnostic terms defined in glossary. LRs calculated from sensitivities and specificities in article. 